\title{
Teneligliptin real-world efficacy assessment of type 2 diabetes mellitus patients in India (TREAT-INDIA study)
}

This article was published in the following Dove Press journal: Diabetes, Metabolic Syndrome and Obesity:Targets and Therapy 8 November 2016

Number of times this article has been viewed

\section{Sujoy Ghosh' \\ Shailesh Trivedi² \\ Debmalya Sanyal ${ }^{3}$ \\ KD Modi ${ }^{4}$ \\ Sandeep Kharb ${ }^{5}$}

'Department of Endocrinology, The Institute of Post Graduate Medical Education and Research (IPGMER), Kolkata, West Bengal, ${ }^{2}$ Anand Hospital, Vadodara, Gujarat, ${ }^{3}$ Department of Endocrinology, KPC Medical College, Kolkata, West Bengal, ${ }^{4} \mathrm{Dr}$ Modi's Clinic (DMC), Department of Endocrinology at Medwin Hospital, Hyderabad, Telangana, ${ }^{5}$ ASIAN

Hospital, Faridabad, Haryana, India
Correspondence: Sujoy Ghosh Department of Endocrinology, The Institute of Post Graduate Medical Education and Research (IPGMER), 244 A.J.C. Bose Road, Kolkata, West Bengal 700020, India Tel +9l 9674625823 Email drsujoyghosh2000@gmail.com
Background and aims: Teneligliptin was introduced in India in May 2015. It has gained popularity and is already widely prescribed in type 2 diabetes mellitus (T2DM). This "real life" data collection was conducted to assess the efficacy of teneligliptin in Indian T2DM patients.

Methods: Predesigned structured proforma was used to collect information from the prescribing physicians regarding the efficacy of teneligliptin when prescribed as monotherapy as well as combination therapy with other antidiabetic drugs in T2DM patients. Information on the glycemic parameters at baseline prior to starting teneligliptin and at the end of 3 months therapy was collected. The efficacy was assessed by analyzing the mean change in 3-month values of glycosylated hemoglobin (HbAlc), fasting plasma glucose (FPG), and postprandial plasma glucose (PPG).

Results: Data of 4305 patients was available for analysis. There was statistically significant improvement in mean $\mathrm{HbA1c}, \mathrm{FPG}$, and PPG with teneligliptin therapy. Means changes in HbA1c, FPG, and PPG were $-1.37 \% \pm 1.15 \%, 51.29 \pm 35.41 \mathrm{mg} / \mathrm{dL}$, and $80.89 \pm 54.27 \mathrm{mg} / \mathrm{dL}$, respectively. Subgroup analysis revealed that $\mathrm{HbA1c}(\%)$ reduction with teneligliptin when used as monotherapy, add-on to metformin or add-on to metformin plus sulfonylureas combination, add-on to metformin plus alpha glucosidase inhibitor combination or add-on to insulin was $0.98 \pm 0.53,1.07 \pm 0.83,1.46 \pm 1.33,1.43 \pm 0.80$, and $1.55 \pm 1.05$, respectively.

Conclusion: Real-world data suggests that teneligliptin significantly improves glycemic control in Indian patients with T2DM when prescribed either as monotherapy or as an add-on to one or more other commonly prescribed antidiabetic drugs.

Keywords: teneligliptin, DPP4 inhibitor, type 2 diabetes mellitus

\section{Introduction}

Diabetes is one of the most challenging health problems of the 21 st century. Around 415 million people worldwide, or $8.8 \%$ of adults, are estimated to have diabetes. About $75 \%$ live in low- and middle-income countries. It is estimated that by 2040 , some 642 million people, or one adult in 10, will have diabetes. This equates to almost 10 million new cases per year. As per the International Diabetes Federation (IDF) 2015 report, India is harboring 69.2 million diabetes patients, second only to China (109.6 million). If the current trends continue, by 2040 India will have about 123.5 million patients with diabetes. ${ }^{1}$

Dipeptidyl peptidase 4 (DPP-4) inhibitor is a relatively new class of antihyperglycemic agents that are now recommended as second- or first-line agents in treatment of diabetes by guidelines like American Diabetes Association (ADA) 2016 and 
American Association of Clinical Endocrinologists and American College of Endocrinology 2016. ${ }^{2,3}$ DPP-4 inhibitors control fasting plasma glucose (FPG) and postprandial plasma glucose (PPG) levels through selective inhibition of DPP-4, resulting in increased plasma concentrations of active glucagon-like peptide-1. DPP-4 inhibitors unlike sulfonylureas, meglitinides, or insulin are weight neutral and no risk of hypoglycaemia. ${ }^{4,5}$

Teneligliptin is a novel DPP-4 inhibitor, having a unique chemical structure which is characterized by five consecutive rings (J-shaped), which might account for its unique potency and half-life time. ${ }^{5,6}$ Teneligliptin was introduced in India in May 2015 and is available at almost one quarter to one fifth of the cost of other DPP-4 inhibitors (namely sitagliptin, vildagliptin, saxagliptin, and linagliptin). In a very short span of time (8-9 months) teneligliptin has become the most widely prescribed DPP-4 inhibitor in India. ${ }^{7}$ Efficacy and safety of teneligliptin has been established in Japanese and Korean populations in several randomized controlled trials with limited sample size..$^{5}$ In India the only data are available in a small phase III clinical trial. ${ }^{8}$

Following its approval for use in clinical practice, this data collection was conducted to assess the efficacy of teneligliptin in Indian type 2 diabetes mellitus (T2DM) patients.

\section{Methods}

Predesigned structured proforma was used for this audit to collect information from the prescribing physicians on the efficacy of teneligliptin when prescribed as either monotherapy or in combination with other antidiabetic drugs. Data collected were anonymized and information collected included demographic data, antidiabetic medications, and glycemic status of the patient at the time of initiation and after 3 months of teneligliptin therapy. Data were collected between September 2015 and December 2015. The glycemic efficacy was assessed by analyzing the mean change in values of glycosylated hemoglobin (HbA1c), FPG, and PPG from baseline following teneligliptin therapy.

\section{Statistical analysis}

Patients' demographic characteristics (age, sex, disease profile, comorbid conditions, and existing medications) and glycemic parameters (HbA1c, FPG, and PPG values for baseline and 3 months) were documented. Descriptive analysis was done for the demographic details. Quantitative data of HbA1c, FPG, and PPG from baseline to 3 months after initiating teneligliptin was analyzed by two-tailed paired $t$-test for data following Gaussian distribution, while paired data not following the Gaussian distribution were analyzed by nonparametric, Wilcoxon signed-rank test. GraphPad Prism5 (version 5.01) statistical software was used for analysis. Statistical tests were considered significant if $P$-value was $<0.05$ at confidence interval of $95 \%$. The data was collected from the pre-existing hospitals records of the participating doctors and data audit was conducted for real world efficacy assessment retrospectively.

\section{Results}

Data of 4305 patients were available for analysis. Table 1 shows the baseline demographic and clinical characteristics.

The mean age of patients was 52.96 \pm 9.9 years and out of the entire patient population $61.23 \%$ were males. Almost $73 \%$ $(\mathrm{n}=3160)$ of patients had comorbid conditions, hypertension (50.69\%), and dyslipidemia (40.95\%) being the most common. Moreover, $20 \%$ of the patients had both hypertension as well as dyslipidemia. Teneligliptin was prescribed mostly as add-on in T2DM patients uncontrolled on previous antidiabetic medications, commonly as add-on to metformin plus sulfonylurea therapy, followed by add-on to metformin therapy, as shown in Table 1 and Figure 1. The commonly prescribed concurrent medications are antihypertensives and statins.

\section{Clinical efficacy of teneligliptin}

At the end of 3 months of teneligliptin therapy, mean $\mathrm{HbA} 1 \mathrm{c}, \mathrm{FPG}$, and PPG were significantly reduced by $1.37 \% \pm 1.15 \%, 51.29 \pm 35.41 \mathrm{mg} / \mathrm{dL}$, and $80.89 \pm 54.27$ $\mathrm{mg} / \mathrm{dL}$, respectively (Table 2 ), and $37.75 \%$ of patients achieved the HbA1c target of $<7 \%$. Significant reduction in $\mathrm{HbA} 1 \mathrm{c}$ by $0.98 \% \pm 0.53 \%$ and $1.07 \% \pm 0.83 \%$ was seen in patients receiving teneligliptin monotherapy and as add-on to metformin, respectively (Figure 2). Teneligliptin as add-on to metformin plus sulfonylurea therapy showed significant $(P$-value $<0.0001)$ reduction in $\mathrm{HbA} 1 \mathrm{c}, \mathrm{FPG}$, and PPG by $1.46 \% \pm 1.33 \%, 53.68 \pm 36.65 \mathrm{mg} / \mathrm{dL}$, and $82.55 \pm 56.51 \mathrm{mg} / \mathrm{dL}$, respectively (Figure 2). In patients receiving teneligliptin monotherapy, $35.48 \%$ of patients achieved HbA1c target of $<7 \%$. While $43.96 \%$ of patients receiving teneligliptin + metformin and $35.03 \%$ of patients receiving teneligliptin + metformin + sulfonylurea achieved the same target. It was also used in combination with insulin with or without other oral antidiabetic drugs (OADs) in 339 patients; where $1.55 \%$ absolute reduction in HbA1c from baseline of $8.98 \% \pm 1.30 \%$ was noted. Teneligliptin effectiveness was analyzed in different categories of the patient population as mentioned in Table 2. 
Table I Baseline demographic and clinical characteristics of all patients

\begin{tabular}{|c|c|}
\hline Patients characteristics & Number of patients, $n$ (\%) \\
\hline Total number of patients & $4305(100)$ \\
\hline \multicolumn{2}{|l|}{ Age (years); mean (SD) - $52.96(9.9)$} \\
\hline$<60$ & $3160(73.40)$ \\
\hline$\geq 60$ & $1145(26.60)$ \\
\hline \multicolumn{2}{|l|}{ Gender } \\
\hline Male & $2636(61.23)$ \\
\hline Female & $1669(38.77)$ \\
\hline \multicolumn{2}{|c|}{ Baseline HbA Ic (\%); mean (SD) - 8.54 (I.I I) } \\
\hline$<7.5$ & $564(13.10)$ \\
\hline$\geq 7.5-\leq 9$ & $2826(65.64)$ \\
\hline$>9$ & $915(21.25)$ \\
\hline \multicolumn{2}{|c|}{ Baseline FPG (mg/dL); mean (SD) - I 72.20 (4I.67) } \\
\hline$\leq 126$ & $365(8.48)$ \\
\hline$>126$ & 3940 (9I.52) \\
\hline \multicolumn{2}{|c|}{ Baseline PPG (mg/dL); mean (SD) - 247.68 (6I.50) } \\
\hline$\leq 200$ & $1112(25.83)$ \\
\hline$>200$ & $3193(74.17)$ \\
\hline \multicolumn{2}{|l|}{ Presence of comorbidities } \\
\hline Hypertension & $2182(50.69)$ \\
\hline Dyslipidemia & $1763(40.95)$ \\
\hline $\mathrm{CV}$ events & $53(1.23)$ \\
\hline Active hepatic disease & $54(1.25)$ \\
\hline Active renal disease & $62(1.44)$ \\
\hline \multicolumn{2}{|l|}{ Antidiabetic medications } \\
\hline Teneligliptin monotherapy & $186(4.32)$ \\
\hline Teneligliptin + metformin & $1208(28.06)$ \\
\hline Teneligliptin + SU & $239(5.55)$ \\
\hline Teneligliptin + metformin $+\mathrm{SU}$ & $1707(39.65)$ \\
\hline Teneligliptin + metformin + AGI & $160(3.71)$ \\
\hline Teneligliptin + metformin $+\mathrm{SU}+\mathrm{AGI}$ & $205(4.76)$ \\
\hline $\begin{array}{l}\text { Teneligliptin + insulin with or without } \\
\text { other antidiabetic drugs }\end{array}$ & $339(7.87)$ \\
\hline Others & $26 I(6.06)$ \\
\hline \multicolumn{2}{|l|}{ Other medications } \\
\hline Antihypertensive & $1946(45.20)$ \\
\hline Statin & $1886(43.81)$ \\
\hline Antiplatelet & $254(5.90)$ \\
\hline Antihypertensive + statin + antiplatelet & $168(3.90)$ \\
\hline
\end{tabular}

Abbreviations: $\mathrm{AGI}$, alpha glucosidase inhibitor; $\mathrm{CV}$, cardiovascular; FPG, fasting plasma glucose; PPG, postprandial plasma glucose; SD, standard deviation; SU, sulfonylureas; HbAlc, glycosylated hemoglobin.

\section{Discussion}

Randomized controlled trials (RCTs) are considered the highest level of evidence in clinical medicine. But often results from RCTs are not replicated in real-world clinical practice. ${ }^{9}$ Real-world evidence supplements RCT data and adds to clinical evidence regarding clinical efficacy of a drug. ${ }^{10}$ Teneligliptin, a DPP-4 inhibitor was added to the armamentarium for use in patients with type 2 diabetes in India. In different clinical trials conducted in Japan, Korea, and India, it has been shown to be safe and effective in T2DM patients when used either as monotherapy or in combination with other conventional OADs. ${ }^{5}$ It is economical as compared with other gliptins (sitagliptin, saxagliptin, vildagliptin, and linagliptin) available in India. The present audit was conducted to assess the efficacy of teneligliptin in a real-world scenario in patients with type 2 diabetes in India.

The average age of the population was $>52$ years and a significant proportion of patients were above 60 years of age (26.60\%). Mean baseline HbA1c level of $8.54 \%$ confirms the high prevalence of uncontrolled glycemic status in patients with T2DM patients in developing countries like India. ${ }^{11}$ Long-term data from major studies like UK Prospective Diabetes Study ${ }^{12}$ has already established the importance of tight and early glucose control to prevent complications of diabetes.

In the teneligliptin monotherapy and combination therapy with other OADs, HbAlc was reduced significantly at 3 months. Similar results were seen with other gliptins like sitagliptin and vildagliptin during real-life observational studies conducted in India and elsewhere. ${ }^{11,13,14}$ Retrospective observational study of sitagliptin conducted by Kubota et al in 741 T2DM Japanese patients showed HbA1c $<7 \%$ achievement at rates of $39.1 \%$ and $38.2 \%$, respectively, in the entire study population ( $\mathrm{n}=741)$, and in patients receiving sitagliptin combination therapy with other OADs $(\mathrm{n}=631) .{ }^{14}$ In this study, the proportion of patients achieving adequate glycemic control is similar to that reported by use of other gliptins in other real-world studies.

Results of teneligliptin monotherapy here are similar also to previous RCTs conducted in Japan (teneligliptin $20 \mathrm{mg}$ monotherapy arm with 79 subjects, and $\mathrm{HbA} 1 \mathrm{c}$ reduction of $0.8 \% \pm 0.1 \%$, compared with baseline at the end of 12 weeks) ${ }^{15}$ and Korea (teneligliptin $20 \mathrm{mg}$ monotherapy arm with 99 subjects, and $\mathrm{HbA} 1 \mathrm{c}$ reduction of $0.90 \% \pm 0.09 \%$, compared with baseline at the end of 24 weeks). ${ }^{16}$

Teneligliptin when used as part of dual therapy with metformin leads to significant $\mathrm{HbAlc}$ reduction of $1.07 \%$ which incidentally is slightly better compared with phase III trials conducted for the same combination in Korean population $(\mathrm{HbA} 1 \mathrm{c}$ reduction of $0.87 \%$ compared to baseline at 16 weeks). ${ }^{17}$ This may be because of a higher baseline HbA1c value of $8.21 \% \pm 0.97 \%$ in our study versus $7.79 \% \pm 0.80 \%$ in the RCT.

In $>95 \%$ of the patients, teneligliptin was used in combination with other classes of antidiabetic drugs. Metformin which is commonly prescribed as first line in diabetes management was received by almost $86 \%$ of patients in this study. Sulfonylureas despite some drawbacks were used in 


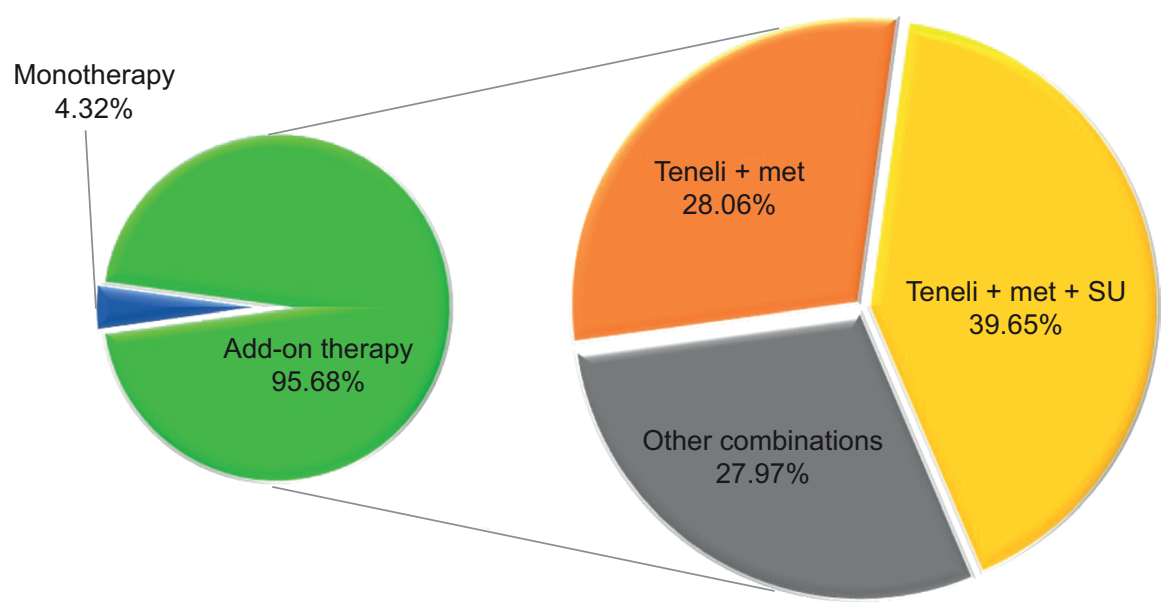

Figure I Use of teneligliptin.

Abbreviations: Met, metformin; SU, sulfonylureas; Teneli, teneligliptin.

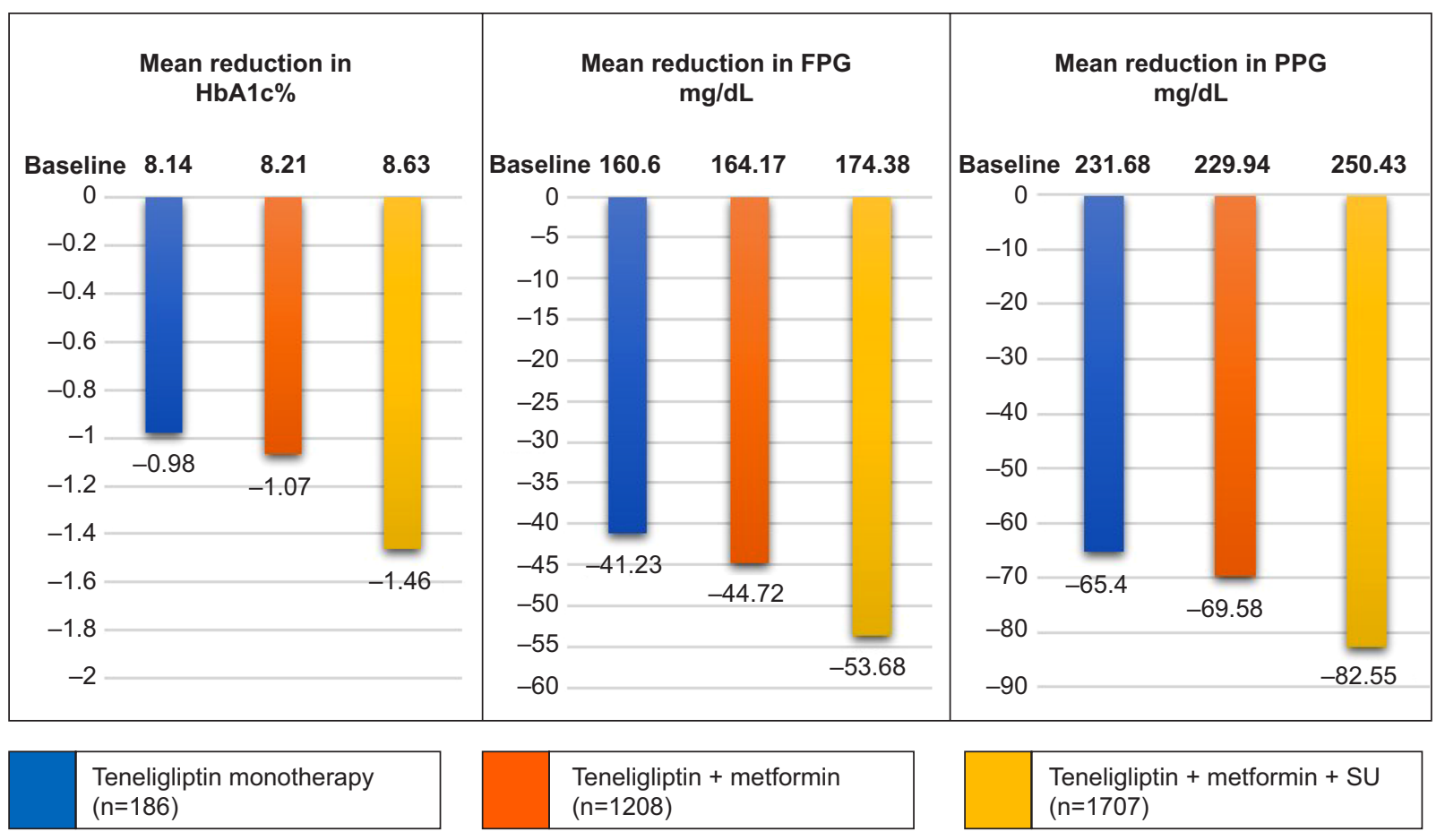

Figure 2 Mean reduction in glycemic parameters at the end of 3 months.

Notes: $P$-value $<0.000$ I for all glycemic parameters in all subgroups.

Abbreviations: FPG, fasting plasma glucose; PPG, postprandial plasma glucose; SU, sulfonylureas.

$>55 \%$ of the patients. ${ }^{3}$ This widespread use of sulfonylureas in Indian patients could be attributed to efficacy and low cost.

The percentages of patients on alpha glucosidase inhibitors (AGIs) and thiazolidinediones (TZDs) were very low $(11.50 \%$ and $5.58 \%$, respectively) compared to other conventional drugs like metformin and Sulfonyureas. This lower proportion of usage may be because of issues related to dosing schedule and gastrointestinal side effects with $\mathrm{AGI}^{18}$ and risk of weight gain with pioglitazone. ${ }^{19} \mathrm{~A}$ few patients had active hepatic and renal disease $(1.25 \%$ and $1.44 \%$, respectively). Because of beneficial pharmacokinetic and pharmacodynamic features, gliptins are recommended to be used in renal dysfunction (even those on hemodialysis) patients albeit with dose modification. But dose modification is not required for linagliptin and teneligliptin in patients with renal dysfunction. ${ }^{20,21}$ Teneligliptin has been studied extensively to assess the pharmacokinetic and safety profile in nondiabetic mild, moderate, and severe renal impairment, and nondiabetic mild to moderate hepatic impairment patients. ${ }^{22,23}$ Moreover, Otsuki et al and Wada et al studies 
Table 2 Mean reduction in glycemic parameters compared to baseline

\begin{tabular}{|c|c|c|c|c|}
\hline Category & FPG (mg/dL) & PPG (mg/dL) & HbAlc (\%) & $\begin{array}{l}\% \text { of patients } \\
\text { achieved, HbA Ic }<7 \%\end{array}$ \\
\hline Overall $(n=4305)$ & $51.29 \pm 35.41$ & $80.89 \pm 54.27$ & $1.37 \pm 1.15$ & 37.75 \\
\hline Teneli + Met + AGI $(n=160)$ & $58.47 \pm 37.23$ & $98.4 I \pm 40.26$ & $1.43 \pm 0.80$ & 51.25 \\
\hline Teneli + Met + SU + AGI (n=205) & $67.88 \pm 51.32$ & $106.45 \pm 73.58$ & $1.81 \pm 1.91$ & 42.45 \\
\hline Teneli + Met + SU + Pio $(n=119)$ & $58.21 \pm 33.83$ & $100.79 \pm 56.37$ & $1.24 \pm 1.87$ & 19.33 \\
\hline Teneli + insulin with or without other OADs $(n=339)$ & $53.73 \pm 37.07$ & $101.03 \pm 71.48$ & $1.55 \pm 1.05$ & 30.08 \\
\hline
\end{tabular}

Note: Values are presented as mean \pm standard deviation otherwise mentioned.

Abbreviations: AGI, alpha glucosidase inhibitor; FPG, fasting plasma glucose; HbAlc, hemoglobin Alc; Met, metformin; OADs, oral antidiabetic drugs; Pio, pioglitazone; PPG, postprandial plasma glucose; SU, sulfonylureas; Teneli, teneligliptin.

have confirmed efficacy and safety of teneligliptin in T2DM patients on hemodialysis..$^{24,25}$

Among different teneligliptin combination therapies, dual therapy of metformin plus teneligliptin was the secondmost commonly used $(28.06 \%)$. This reflects the changing prescribing habits of medical practitioners, possibly adopting the safer option of gliptins. Because of emergence of many gliptins and availability of affordable teneligliptin in India, it is imminent to have comparison between overall safety and efficacy of gliptins with sulfonylureas. Comparable efficacy between gliptins and sulfonylureas when either is added to metformin has been proved in different meta-analyses. ${ }^{26-28} \mathrm{In}$ terms of safety related to risk of hypoglycemia, cardiovascular events, and weight gain, gliptins score over sulfonylureas when used both as monotherapy or as add-on to ongoing metformin therapy. ${ }^{26,29}$ Most patients (53.61\%) were on three or more antidiabetic drugs indicating that patients had had the disease for a significant duration. Robust glycemic benefit in such patients with diabetes of significant duration and poor glycemic status reemphasizes that teneligliptin is a potent/ efficacious drug for treatment of patients with type 2 diabetes. This finding also supports, and is in line with, the findings of the UKPDS study which suggested that polypharmacy is required to attain glycemic targets in patients with type 2 diabetes. ${ }^{30}$

The reduction in glycemic parameters strongly correlated with baseline glycemic values, that is, higher the $\mathrm{HbAlc}$ at baseline; higher was the reduction at the end of 3 months. Similarly, the HbA1c reduction also correlated strongly with the presence of the number of concomitant antidiabetic medications. HbA1c reduced by $0.98 \%, 1.11 \%$, $1.51 \%, 1.62 \%$, and $1.65 \%$ in patients receiving one-drug therapy (teneligliptin monotherapy), two-, three-, four-, and five-drug therapies with teneligliptin, respectively, at the end of 3 months compared with baseline. Similar incremental reduction in FPG and PPG was observed relative to corresponding baseline values and depending on the number of antidiabetic drugs patients received. Only a small number of patients had an increase or no change in glycemic parameters (HbA1c, FPG, and PPG) compared with baseline $(0.86 \%-1.18 \%)$.

The majority of patients ( $>73 \%$ ) had one or more comorbid condition like hypertension and dyslipidemia. This high prevalence of comorbid conditions in this study is in accordance with previously reported studies done in India. ${ }^{31}$ Both hypertension and dyslipidemia management are an important part of comprehensive diabetes care to reduce the overall cardiovascular risk in diabetes patients. Our data suggest almost all hypertensive and dyslipidemic patients were receiving antihypertensives $(45.20 \%)$ and statins (43.81\%). However, the use of statins seems to be below par considering the recent recommendations by the American College of Cardiology/American Heart Association guideline on the treatment of blood cholesterol for diabetes patients. ${ }^{32}$

This retrospective study has certain limitations. Because of the observational and retrospective design of the study, the possibility of selection bias cannot be ruled out. Information related to diet and lifestyle modification and information regarding dosing pattern of concomitant medication was not analyzed. It is not possible to comment on dropouts and adverse events. Data were collected only for a duration of 3 months, so there are limitations in commenting on durability of the treatment. Long-term studies to address the shortcomings of the present study are warranted.

\section{Conclusion}

Results from this real-world retrospective data on teneligliptin in India have demonstrated that teneligliptin significantly improves glycemic parameters in Indian T2DM patients when prescribed as monotherapy or as add-on to one or more antidiabetic drugs.

\section{Acknowledgments}

The authors would like to acknowledge the contribution of the doctors all over India who provided data for this audit. 
This audit was supported by the medical team of Glenmark Pharmaceutical.

\section{Disclosure}

The authors report no conflicts of interest in this work.

\section{References}

1. International diabetes federation. IDF Diabetes Atlas, 7 th edn. Brussels, Belgium: International Diabetes Federation, 2015. Available from: http://www.diabetesatlas.org. Accessed July 27, 2016.

2. American Diabetes Association. Standards of medical care in diabetes 2016. Diabetes Care. 2016;39(Suppl 1):S1-S106.

3. Garber AJ, Abrahamson MJ, Barzilay JI, et al. Consensus statement by the American Association of Clinical endocrinologists and American College of Endocrinology on the comprehensive type 2 diabetes management algorithm - 2016 executive summary. Endocr Pract. 2016;22(1):84-113.

4. Eto T, Inoue S, Kadowaki T. Effects of once-daily teneligliptin on 24-h blood glucose control and safety in Japanese patients with type 2 diabetes mellitus: a 4-week, randomized, double-blind, placebo-controlled trial. Diabetes Obes Metab. 2012;14(11):1040-1046.

5. Scott LJ. Teneligliptin: a review in type 2 diabetes. Clin Drug Investig. 2015;35(11):765-772.

6. Kutoh E, Hirate M, Ikeno Y. Teneligliptin as an initial therapy for newly diagnosed, drug naive subjects with type 2 diabetes. J Clin Med Res. 2014;6(4):287-294.

7. ORG-IMS June'2016. Available from: https://www.imshealth.com/en/ about-us/news/top-line-market-data. Accessed July 27,2016.

8. CTRI/2014/01/004315. Available from: http://ctri.nic.in/Clinicaltrials/pmaindet2.php?trialid=8318\&EncHid=\&userName=teneligliptin. Accessed August 24, 2016.

9. Silverman SL. From randomized controlled trials to observational studies. Am J Med. 2009;122(2):114-120.

10. Sahay BK, Seshiah V. Importance of observational studies in understanding regional clinical practice: rationale and design of the A1chieve study. J Assoc Physicians India. 2013;61(1 Suppl):6-8.

11. Mathieu C, Barnett AH, Brath H, et al. Effectiveness and tolerability of second-line therapy with vildagliptin vs. other oral agents in type 2 diabetes: a real-life worldwide observational study (EDGE). Int J Clin Pract. 2013;67(10):947-956.

12. Holman RR, Paul SK, Bethel MA, Matthews DR, Neil HA. 10-year follow-up of intensive glucose control in type 2 diabetes. NEngl J Med. 2008;359(15):1577-1589.

13. Saglietti G, Placentino G, Schellino A. Observational study on dipeptidyl peptidase-4 inhibitors: a real-life analysis on 360 patients from the ASL VCO territory in Italy. Clin Drug Investig. 2014;34(7):513-519.

14. Kubota A, Maeda H, Kanamori A, et al. Efficacy and safety of sitagliptin monotherapy and combination therapy in Japanese type 2 diabetes patients. J Diabetes Investig. 2012;3(6):503-509.

15. Kadowaki T, Kondo K. Efficacy, safety and dose-response relationship of teneligliptin, a dipeptidyl peptidase-4 inhibitor, in Japanese patients with type 2 diabetes mellitus. Diabetes Obes Metab. 2013;15(9):810-818.

16. Hong S, Park CY, Han KA, et al. Efficacy and safety of teneligliptin, a novel dipeptidyl peptidase-4 inhibitor, in Korean patients with type 2 diabetes mellitus: a 24-week multicentre, randomized, double-blind, placebocontrolled phase III trial. Diabetes Obes Metab. 2016;18(5):528-532.
17. Kim MK, Rhee EJ, Han KA, et al. Efficacy and safety of teneligliptin: a dipeptidyl peptidase 4 inhibitor, combined with metformin in Korean patients with type 2 diabetes mellitus: a 16-week, randomized, double-blind, placebo-controlled phase III trial. Diabetes Obes Metab. 2015;17(3):309-312.

18. Stein SA, Lamos EM, Davis SN. A review of the efficacy and safety of oral antidiabetic drugs. Expert Opin Drug Saf. 2013;12(2):153-175

19. Bosetti C, Rosato V, Buniato D, Zambon A, La Vecchia C, Corrao G. Cancer risk for patients using thiazolidinediones for type 2 diabetes: a meta-analysis. Oncologist. 2013;18(2):148-156.

20. Abe M, Okada K. DPP-4 inhibitors in diabetic patients with chronic kidney disease and end-stage kidney disease on dialysis in clinical practice. Contrib Nephrol. 2015;185:98-115.

21. Nakamura Y, Hasegawa H, Tsuji M, et al. Diabetes therapies in hemodialysis patients: dipeptidase-4 inhibitors. World J Diabetes. 2015;6(6):840-849.

22. Halabi A, Maatouk H, Siegler KE, Faisst N, Lufft V, Klause N. Pharmacokinetics of teneligliptin in subjects with renal impairment. Clin Pharmacol Drug Dev. 2013;2(3):246-254

23. Halabi A, Maatouk H, Siegler KE, Faisst N, Hinrichsen H. Pharmacokinetics and safety of teneligliptin in subjects with hepatic impairment. Clin Pharmacol Drug Dev. 2013;3(4):290-296.

24. Otsuki H, Kosaka T, Nakamura K, Shimomura F, Kuwahara Y, Tsukamoto T. Safety and efficacy of teneligliptin: a novel DPP-4 inhibitor for hemodialysis patients with type 2 diabetes. Int Urol Nephrol. 2014;46(2):427-432.

25. Wada N, Mori K, Nakagawa C, et al. Improved glycemic control with teneligliptin in patients with type 2 diabetes mellitus on hemodialysis: evaluation by continuous glucose monitoring. J Diabetes Complications. 2015;29(8):1310-1313.

26. Deacon CF, Lebovitz HE. Comparative review of dipeptidyl peptidase-4 inhibitors and sulphonylureas. Diabetes Obes Metab. 2016;18(4): 333-347.

27. Foroutan N, Muratov S, Levine M. Safety and efficacy of dipeptidyl peptidase-4 inhibitors vs sulfonylurea in metformin-based combination therapy for type 2 diabetes mellitus: systematic review and metaanalysis. Clin Invest Med. 2016;39(2):E48-E62.

28. Karagiannis T, Paschos P, Paletas K, Matthews DR, Tsapas A. Dipeptidyl peptidase-4 inhibitors for treatment of type 2 diabetes mellitus in the clinical setting: systematic review and meta-analysis. $B M J$. 2012;344:e1369.

29. Ou SM, Shih CJ, Chao PW, et al. Effects on clinical outcomes of adding dipeptidyl peptidase-4 inhibitors versus sulfonylureas to metformin therapy in patients with type 2 diabetes mellitus. Ann Intern Med. 2015;163(9):663-672.

30. Turner RC, Cull CA, Frighi V, Holman RR. Glycemic control with diet, sulfonylurea, metformin, or insulin in patients with type 2 diabetes mellitus: progressive requirement for multiple therapies (UKPDS 49). UK Prospective Diabetes Study (UKPDS) Group. JAMA. 2000;281(21):2005-2012.

31. Yadav D, Mishra M, Tiwari A, Bisen PS, Goswamy HM, Prasad GB. Prevalence of dyslipidemia and hypertension in Indian type 2 diabetic patients with metabolic syndrome and its clinical significance. Osong Public Health Res Perspect. 2014;5(3):169-175.

32. Stone NJ, Robinson JG, Lichtenstein AH, et al. 2013 ACC/AHA guideline on the treatment of blood cholesterol to reduce atherosclerotic cardiovascular risk in adults: a report of the American College of Cardiology/American Heart Association Task Force on Practice Guidelines. Circulation. 2014;129(25 Supp1 2):S1-S45. 
Diabetes, Metabolic Syndrome and Obesity: Targets and Therapy

Diabetes, Metabolic Syndrome and Obesity: Targets and Therapy is an international, peer-reviewed open-access journal committed to the rapid publication of the latest laboratory and clinical findings in the fields of diabetes, metabolic syndrome and obesity research Original research, review, case reports, hypothesis formation, expert opinion and commentaries are all considered for publication. The manuscript management system is completely online and includes a very quick and fair peer-review system, which is all easy to use. Visit http://www.dovepress.com/testimonials.php to read real quotes from published authors.

Submit your manuscript here: https://www.dovepress.com/diabetes-metabolic-syndrome-and-obesity-targets-and-therapy-journal 